\title{
Effects of continuous infusion of etomidate at various dose rates on adrenal function in dogs
}

\author{
Bangyong Qin*, Hongzhuan Hu, Baofeng Cao and Zhaoqiong Zhu
}

\begin{abstract}
Background: Etomidate is a commonly used sedative in intravenous anesthesia. The aim of this study was to compare the effects of various etomidate doses administered by continuous infusion on adrenal function in dogs under general anesthesia.

Methods: Thirty-six healthy adult male dogs were randomly divided into six groups. Sodium pentobarbital alone was administered to the control group (group C); five experimental groups $\left(E_{1}, E_{2}, E_{3}, E_{4}\right.$, and $E_{5}$ ) were also given etomidate at doses of $10,15,20,25$, and $30 \mu \mathrm{g} \cdot \mathrm{kg}^{-1} \cdot \mathrm{min}^{-1}$, respectively, to maintain anesthesia. Heart rate (HR), mean arterial pressure (MAP), and bispectral index (BIS) were monitored. Serum cortisol, aldosterone, adrenaline, and noradrenaline levels were measured, and HR, MAP, and BIS values recorded, before intubation $\left(T_{0}\right)$, and at $1 \mathrm{~h}, 2 \mathrm{~h}$, and $3 \mathrm{~h}$ after intubation $\left(T_{1-3}\right)$.

Results: Cortisol and aldosterone levels in groups $\mathrm{E}_{1-5}$ decreased as the doses and times of continuous infusion of etomidate increased. The cortisol level was significantly decreased compared with baseline at $T_{3}$ in group $E_{1}$ and at $T_{1-3}$ in groups $E_{2-5}(P<0.05)$. Compared with the corresponding levels in group $C$, cortisol levels were significantly lower than $T_{0}$ values at $T_{3}$ in group $E_{1}$ and at $T_{1-3}$ in groups $E_{2-5}(P<0.05)$. The aldosterone level was significantly lower at $T_{3}$ in group $E_{2}$ and at $T_{1-3}$ in groups $E_{3-5}(P<0.05)$. Significant reductions in cortisol levels at $T_{2-3}$ in group $E_{2}$ and at $T_{1-3}$ in groups $E_{3-5}$ compared with group $C$ were also observed $(P<0.05)$. The plasma adrenaline and noradrenaline levels, $H R$, MAP, and BIS in groups $E_{1-5}$ were within the normal range at the different times and with the different doses $(P>0.05)$.

Conclusions: Cortisol and aldosterone levels decreased with time and continuous infusion of etomidate; there were no significant changes in adrenaline and noradrenaline levels, HR, MAP, and BIS in any group.
\end{abstract}

Keywords: Intravenous anesthesia, Etomidate, Adrenal function

\section{Background}

Etomidate is a short-acting sedative with rapid onset of effects that is commonly used for inducing short-term anesthesia prior to intubation in patients. Advantages of this general anesthetic agent include rapid recovery of consciousness and minimal influence on tidal volume and systemic pressure. It is safe and especially suitable for patients with coronary heart disease, hypertension, old age, or shock [1,2]. Etomidate is an intravenous induction agent that is associated with hemodynamic stability following administration [3, 4]. Compared with

\footnotetext{
* Correspondence: bangyongqin@126.com

Department of Anesthesiology, Affliated Hospital of Zunyi Medical College, No. 149 Dalian Road, Zunyi, Guizhou Province 563003, China
}

propofol, etomidate shows greater hemodynamic stability after induction of anesthesia, and may be preferred over propofol for general anesthesia [5]. Etomidate should be considered for induction of anesthesia in cardiac surgery patients $[5,6]$. One of the most common-but important-side effects of this drug is the suppression of steroid production by the reversible inhibition of the 11-betahydroxylase enzyme [3]. Etomidate is rarely used to maintain anesthesia because of this adrenal suppression [7]. However, some studies have reported that when administered to induce anesthesia, the suppression is transient, and others have noted no significant inhibitory effect on adrenocortical function in patients with severe sepsis or septic shock [8-10]. The pros and cons of etomidate 
Table 1 Six group dogs cortisol, aldosterone concentration change and comparison $(n=6, \bar{x} \pm s)$

\begin{tabular}{llllll}
\hline Index & Group & $T_{0}$ & $T_{1}$ & $T_{2}$ & $T_{3}$ \\
\hline Cortisol $(\mathrm{ng} / \mathrm{ml})$ & C & $253.73 \pm 23.87$ & $246.76 \pm 16.95$ & $247.88 \pm 16.81$ & $251.53 \pm 18.62$ \\
& E1 & $254.10 \pm 22.10$ & $247.70 \pm 21.24$ & $240.95 \pm 20.71$ & $222.72 \pm 19.87^{* \#}$ \\
& E2 & $249.25 \pm 17.15$ & $215.40 \pm 19.51^{\text {*\# }}$ & $181.32 \pm 14.89^{* \#}$ & $159.63 \pm 18.47^{* \#}$ \\
& E3 & $248.43 \pm 16.99$ & $193.33 \pm 17.95^{* \#}$ & $161.31 \pm 17.43^{* \#}$ & $120.14 \pm 18.05^{* \#}$ \\
& E4 & $249.72 \pm 20.41$ & $182.80 \pm 19.14^{* \#}$ & $148.80 \pm 17.42^{* \#}$ & $116.33 \pm 10.84^{* \#}$ \\
Aldosterone $(\mathrm{pg} / \mathrm{ml})$ & E5 & $248.28 \pm 23.02$ & $165.32 \pm 20.56^{* \#}$ & $126.43 \pm 16.82^{* \#}$ & $85.69 \pm 12.90^{* \#}$ \\
& C & $133.93 \pm 14.37$ & $129.15 \pm 18.78$ & $124.89 \pm 14.00$ & $129.83 \pm 11.23$ \\
& E1 & $140.54 \pm 19.63$ & $134.77 \pm 18.35$ & $128.48 \pm 16.74$ & $113.81 \pm 16.67$ \\
& E2 & $135.76 \pm 15.01$ & $119.28 \pm 12.01$ & $100.98 \pm 12.65^{\#}$ & $79.70 \pm 11.66^{* \#}$ \\
E3 & $129.61 \pm 16.51$ & $105.24 \pm 15.30^{* \#}$ & $80.98 \pm 15.80^{* \#}$ & $64.28 \pm 11.88^{* \#}$ \\
& E4 & $136.29 \pm 16.52$ & $102.07 \pm 16.28^{* \#}$ & $75.95 \pm 11.34^{* \#}$ & $59.37 \pm 8.98^{* \#}$ \\
E5 & $128.55 \pm 26.43$ & $93.66 \pm 25.79^{* \#}$ & $69.87 \pm 18.70^{* \#}$ & $55.35 \pm 13.18^{* \#}$ \\
\hline
\end{tabular}

And $\mathrm{T}_{0}$ comparison, ${ }^{*} P<0.05$; and $C$ group comparison, ${ }^{\#} P<0.05$

continue to be discussed, and its use remains controversial [11-13]. The objective of this study was to evaluate the effects of continuous infusion of various doses of etomidate on adrenal function in dogs. Therefore, applications and disadvantages of etomidate relying on disputed, especially whether they have a significant effect on adrenal function. Our research aims to provide reference for clinical application.

\section{Methods}

\section{Animals and groups}

All procedures were conducted in accordance with the rules and regulations of the Subcommittee on Research Animal Care at Zunyi Medical College. Thirty-six healthy adult male mongrel dogs of the same breed, eight to 12 months of age, and weighing $10 \pm 2.5 \mathrm{~kg}$ were used for the study. The dogs were fasted $12 \mathrm{~h}$ prior to the experiment and were randomly divided into six groups. Dogs in the control group (group C) were anesthetized with sodium pentobarbital only. Dogs in experimental groups $\left(\mathrm{E}_{1}, \mathrm{E}_{2}, \mathrm{E}_{3}, \mathrm{E}_{4}\right.$, and $\left.\mathrm{E}_{5}\right)$ underwent induction of anesthesia and were intubated using sodium pentobarbital and then maintained under anesthesia for $3 \mathrm{~h}$ with a continuous infusion of etomidate at doses of $10,15,20,25$, and $30 \mu \mathrm{g} \cdot \mathrm{kg}^{-1} \cdot \mathrm{min}^{-1}$, respectively. This study was carried out in strict accordance with the recommendations in the Guide for the Care and Use of Laboratory Animals of the National Institutes of Health. The animal use protocol has been reviewed and approved by the Institutional Animal Care and Use Committee (IACUC) of Zunyi Medical College.

\section{Medicines and instruments}

Etomidate was obtained from Xuzhou Enhua Pharmaceutical Co., Ltd. (batch number: 20100430), and vecuronium bromide (it is no histamine release and little effect on hemodynamics and cheap [14]) was obtained from Zhejiang Xianju Pharmaceutical Co., Ltd. (batch number: 100503). An RY-R type anesthesia machine was purchased from Jiangsu Kaitai Medical Equipment Co., Ltd. A multi-function monitor (UT4000Fpro) was purchased from Shenzhen Kaitai Industry Co., Ltd., and UP8000 depth of anesthesia monitors were purchased from the Shenzhen Kerui Kang Industrial Co., Ltd. The manufacturers is GC-2010yRadio immunity counter, University of Science and Technology of China science and Technology Industrial Corporation.

\section{Anesthetic methods}

The dogs were pre-treated with $2.5 \%$ sodium pentobarbital $(25,000 \mu \mathrm{g} / \mathrm{kg})$ intraperitoneally at $8: 15$ to $8: 30 \mathrm{on}$ the procedure day, and catheters were placed in the right femoral artery and vein. Sodium heparin $(3000 \mu \mathrm{g} / \mathrm{kg})$ was infused via a central venous line, and mean arterial pressure (MAP), heart rate (HR), and bispectral index (BIS) were monitored. Animals were heparinized to facilitate the collection of blood samples. Group C animals were anesthetized with $2.5 \%$ sodium pentobarbital $(500 \mu \mathrm{g} / \mathrm{kg})$ and supplemented at appropriate intervals by intraperitoneal injection to maintain a BIS value of 40-60 (it is depth of anesthesia and close clinical anesthesia state). In addition to sodium pentobarbital, dogs in the five experimental groups $\left(E_{1}, E_{2}, E_{3}, E\right.$, and $E_{5}$ ) received infusions of etomidate at doses of 10, 15, 20,25 , and $30 \mu \mathrm{g} \cdot \mathrm{kg}^{-1} \cdot \mathrm{min}^{-1}$, respectively, and were maintained under anesthesia for $3 \mathrm{~h}$. Respiratory parameters were set as follows: tidal volume, $15 \mathrm{~mL} / \mathrm{kg}$; respiratory rate, 15-18 times per minute; I:E, 1:2; oxygen flow rate, $2 \mathrm{~L} / \mathrm{min}$; and $\mathrm{P}_{\mathrm{ET}} \mathrm{CO}_{2}, 4.66-5.99 \mathrm{kPa}$. Each dog received $4-6 \mathrm{~mL} \cdot \mathrm{kg}^{-1} \cdot \mathrm{h}^{-1}$ Lactated Ringer's solution IV to maintain the central venous pressure (CVP) between 6 and $10 \mathrm{cmH}_{2} \mathrm{O}$. Subsequently intermittent boluses of 
vecuronium bromide $(50 \mu \mathrm{g} / \mathrm{kg})$ were administered for neuromuscular blockade to maintain the muscle relaxant. The temperature of the controlled laboratory was $23{ }^{\circ} \mathrm{C}$ and the animals' temperature was $37-38^{\circ} \mathrm{C}$.

\section{Observation indexes}

Blood samples were collected from the right femoral vein at time points $T_{0}$ to $T_{3}$ for radioimmunoassay analysis of serum cortisol, aldosterone, adrenaline, and noradrenaline concentrations [15]. MAP, HR, and BIS were recorded at the same time points. Indeed, the half-life of serum cortisol, serum aldosterone and ACTH in human blood is $70 \mathrm{~min} \mathrm{[16],} 20 \mathrm{~min}$ [17], and $10 \mathrm{~min} \mathrm{[18],}$ respectively.

\section{Statistical analysis}

All data are reported as the mean \pm SD. Statistical analyses were performed using SPSS17.0 software. Single factor analysis of variance was compared between groups. Pair-wise comparisons underwent post hoc testing with Dunnett's $t$ test. For all statistical analyses, $P<0.05$ indicated statistical significance.

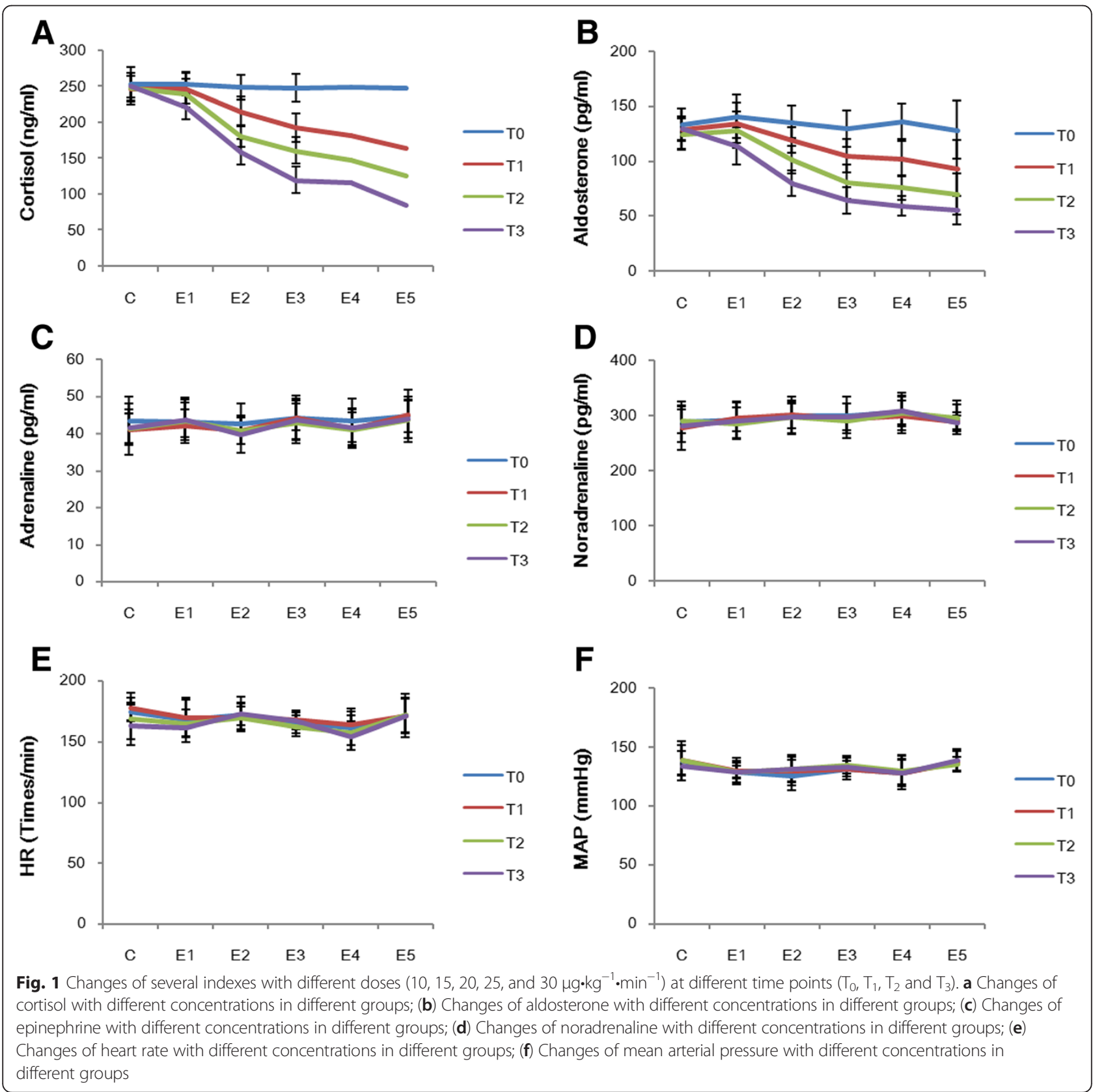


Table 2 The plasma epinephrine, norepinephrine concentration and HR, MAP, BIS value in six group dogs $(n=6, \bar{x} \pm s)$

\begin{tabular}{|c|c|c|c|c|c|}
\hline Index & Group & $\mathrm{T}_{0}$ & $\mathrm{~T}_{1}$ & $\mathrm{~T}_{2}$ & $T_{3}$ \\
\hline \multirow[t]{6}{*}{ Adrenaline (pg/ml) } & $C$ & $43.53 \pm 6.24$ & $41.09 \pm 6.91$ & $41.29 \pm 4.04$ & $41.66 \pm 4.87$ \\
\hline & E1 & $43.32 \pm 5.85$ & $42.28 \pm 4.22$ & $43.61 \pm 4.73$ & $43.87 \pm 5.70$ \\
\hline & E2 & $42.65 \pm 5.39$ & $40.73 \pm 3.68$ & $40.87 \pm 3.68$ & $39.82 \pm 5.02$ \\
\hline & E3 & $44.29 \pm 5.77$ & $44.37 \pm 3.64$ & $43.05 \pm 5.72$ & $43.87 \pm 5.56$ \\
\hline & E4 & $43.50 \pm 5.89$ & $41.49 \pm 5.31$ & $41.05 \pm 4.71$ & $41.66 \pm 4.72$ \\
\hline & E5 & $44.73 \pm 7.10$ & $45.08 \pm 4.89$ & $43.73 \pm 4.98$ & $43.96 \pm 5.26$ \\
\hline \multirow[t]{6}{*}{ Noradrenaline (pg/ml) } & C & $288.86 \pm 36.37$ & $277.90 \pm 40.30$ & $291.46 \pm 23.99$ & $281.36 \pm 29.27$ \\
\hline & E1 & $292.10 \pm 32.97$ & $297.13 \pm 25.21$ & $285.51 \pm 29.30$ & $291.17 \pm 32.93$ \\
\hline & E2 & $300.00 \pm 34.08$ & $301.12 \pm 24.32$ & $298.77 \pm 22.61$ & $297.21 \pm 30.30$ \\
\hline & E3 & $300.43 \pm 32.74$ & $295.03 \pm 26.47$ & $290.53 \pm 31.35$ & $297.63 \pm 24.39$ \\
\hline & E4 & $306.56 \pm 33.67$ & $300.71 \pm 33.29$ & $305.37 \pm 21.80$ & $307.97 \pm 27.67$ \\
\hline & E5 & $292.54 \pm 27.16$ & $288.37 \pm 16.86$ & $296.69 \pm 30.30$ & $287.81 \pm 12.12$ \\
\hline \multirow[t]{6}{*}{ HR (Times/min) } & $C$ & $174.50 \pm 7.48$ & $178.17 \pm 11.6$ & $169.00 \pm 16.82$ & $163.33 \pm 16.53$ \\
\hline & E1 & $168.00 \pm 18.17$ & $169.50 \pm 14.99$ & $165.00 \pm 11.49$ & $162.00 \pm 7.54$ \\
\hline & E2 & $172.33 \pm 9.25$ & $169.50 \pm 9.14$ & $170.00 \pm 11.45$ & $172.67 \pm 13.71$ \\
\hline & E3 & $165.33 \pm 8.21$ & $168.33 \pm 6.83$ & $162.83 \pm 8.38$ & $167.67 \pm 7.42$ \\
\hline & E4 & $161.83 \pm 15.15$ & $164.33 \pm 9.95$ & $157.33 \pm 14.15$ & $154.67 \pm 12.00$ \\
\hline & E5 & $171.00 \pm 13.76$ & $171.00 \pm 17.82$ & $172.00 \pm 14.30$ & $171.33 \pm 14.68$ \\
\hline \multirow[t]{6}{*}{ MAP (mmHg) } & C & $138.00 \pm 16.57$ & $138.67 \pm 12.79$ & $139.00 \pm 12.77$ & $134.17 \pm 12.70$ \\
\hline & E1 & $129.33 \pm 11.04$ & $129.83 \pm 6.74$ & $128.83 \pm 9.17$ & $128.83 \pm 5.04$ \\
\hline & E2 & $125.83 \pm 12.86$ & $129.83 \pm 12.92$ & $131.50 \pm 11.31$ & $131.17 \pm 10.42$ \\
\hline & E3 & $131.50 \pm 9.48$ & $131.83 \pm 6.68$ & $134.67 \pm 7.23$ & $133.33 \pm 8.31$ \\
\hline & E4 & $128.33 \pm 11.22$ & $128.50 \pm 14.36$ & $130.17 \pm 12.35$ & $127.83 \pm 11.39$ \\
\hline & E5 & $138.50 \pm 8.34$ & $137.67 \pm 9.00$ & $135.50 \pm 5.86$ & $139.00 \pm 9.14$ \\
\hline \multirow[t]{6}{*}{ BIS } & $C$ & $47.67 \pm 3.33$ & $47.50 \pm 1.76$ & $48.17 \pm 2.93$ & $46.83 \pm 3.66$ \\
\hline & E1 & $46.50 \pm 5.05$ & $47.50 \pm 4.76$ & $46.50 \pm 4.59$ & $48.17 \pm 5.49$ \\
\hline & E2 & $43.83 \pm 3.06$ & $45.83 \pm 4.12$ & $44.50 \pm 2.81$ & $45.00 \pm 3.10$ \\
\hline & E3 & $47.33 \pm 3.72$ & $46.67 \pm 3.39$ & $49.33 \pm 3.39$ & $49.83 \pm 5.04$ \\
\hline & E4 & $48.00 \pm 2.61$ & $45.17 \pm 3.66$ & $46.83 \pm 3.06$ & $43.83 \pm 2.48$ \\
\hline & E5 & $45.33 \pm 4.10$ & $44.83 \pm 2.86$ & $44.17 \pm 3.13$ & $44.00 \pm 2.45$ \\
\hline
\end{tabular}

\section{Results}

\section{Cortisol and aldosterone levels}

Results are summarized in Table 1 (Fig. 1). The cortisol and aldosterone levels in groups $\mathrm{E}_{1-5}$ decreased as the dose of etomidate and length of infusion time increased. Compared with $\mathrm{T}_{0}$ values, the cortisol level was significantly decreased at $\mathrm{T}_{3}$ in group $\mathrm{E}_{1}$ and at $\mathrm{T}_{1-3}$ in groups $\mathrm{E}_{2-5}(P<0.05)$. For example, the level was $215.40 \pm 19.51$ in group $E_{2}$ significantly lower than the corresponding level $(246.76 \pm 16.95)$ in group C. Compared with group $\mathrm{C}$, cortisol was significantly decreased relative to $T_{0}$ values at $T_{3}$ in group $E_{1}$ and at $\mathrm{T}_{1-3}$ in groups $\mathrm{E}_{2-5} \quad(P<0.05)$. The aldosterone level was significantly decreased at $T_{3}$ in group $E_{2}$ and at $\mathrm{T}_{1-3}$ in groups $\mathrm{E}_{3-5}(P<0.05)$; in comparison with the corresponding values in group $C$, the aldosterone levels were significantly lower at $\mathrm{T}_{2-3}$ in group $\mathrm{E}_{2}$ and at $\mathrm{T}_{1-3}$ in groups $\mathrm{E}_{3-5}(P<0.05)$. Compared with the values in group $\mathrm{C}$, serum cortisol and aldosterone concentrations in groups $\mathrm{E}_{1}-\mathrm{E}_{5}$ demonstrated a dose-dependent reduction $(P<0.05)$ (Table 1 and Fig. 1$)$.

\section{Adrenaline and noradrenaline levels}

Results are summarized in Table 2 (Fig. 1). The plasma adrenaline and noradrenaline levels in groups $\mathrm{E}_{1-5}$ were within the normal range at the different times and doses $(P>0.05)$.

\section{Hemodynamics and BIS}

Results are summarized in Table 2 (Fig. 1). HR, MAP, and $\mathrm{BIS}$ values in groups $\mathrm{E}_{1-5}$ were within the normal range at the different times and doses $(P>0.05)$. 


\section{Discussion}

Etomidate was introduced into clinical practice in 1972, and initial reports of its use in humans emerged in the clinical literature soon afterward [19]. Etomidate is the only imidazole among the general anesthesia induction drugs, and it has the most favorable therapeutic index for single bolus administration $[4,6]$. Etomidate induces less apnea than barbiturates or propofol, does not cause histamine release, and very rarely causes allergic reactions $[5,20]$. Because of its remarkably benign hemodynamic effects, etomidate has proven useful for general anesthetic induction in patients undergoing cardiac surgery and those with poor cardiac function [21, 22]. The major molecular targets mediating the anesthetic effects of etomidate in the central nervous system are specific $\gamma$-aminobutyric acid type A receptor subtypes. It also produces a unique toxicity among anesthetic drugs: inhibition of adrenal steroid synthesis that far outlasts its hypnotic action [20]. Adrenal cortical inhibition by etomidate has received a great deal of attention and significantly limits its use as both an anesthetic and a sedative [23, 24]. A vigorous debate regarding the use of etomidate for intubation continues [25, 26].

The adrenal cortex secretes cortisol and aldosterone, and their concentrations may reflect adrenocortical function. Because cortisol has a circadian rhythm, we induced anesthesia at the same time every day during our study. We designed our experiments which references for the clinical dose range $10-20 \mu \mathrm{g} \cdot \mathrm{kg}^{-1} \cdot \mathrm{min}^{-1}$ of etomidate and dog doses equivalent to the human 1.88 times [20]. The cortisol and aldosterone levels in groups $\mathrm{E}_{1-5}$ demonstrated time- and dose-dependent reductions with the continuous infusion of etomidate. Our results therefore show that intravenous infusion of etomidate can inhibit adrenal cortical functions. The adrenal medulla secretes epinephrine and norepinephrine. Catecholamines are important indicators of the stress response and have obvious correlations with hemodynamic changes. In our study, plasma epinephrine and norepinephrine concentrations stayed within normal ranges in the experimental dogs and there were no statistically significant differences at the various times in the control group. HR and MAP remained within normal ranges as etomidate doses and times increased. Etomidate anesthesia does not have a significant effect on perioperative epinephrine and norepinephrine levels. Etomidate, used as a continuous infusion at $10-30 \mu \mathrm{g} \cdot \mathrm{kg}^{-1} \cdot \mathrm{min}^{-1}$ for colonoscopy can maintain a good depth of anesthesia and results in faster recovery than propofol-remifentanil sedation [27]. Etomidate also can maintain good clinical anesthesia depth (BIS value) as the dose increases. In our study, BIS values showed minimal change with different doses of etomidate, probably because of the lack of surgical stimulation and the use of a muscle relaxant.
Meanwhile, experiments were carried out under isothermal conditions which did not affect the results. Although the altered temperature may affect the depth of anesthesia, we carefully monitored the temperature of dogs during the experiment.

Our study used continuous infusion of different doses of etomidate in dogs and determined that serum cortisol and aldosterone levels were decreased as the time and doses of etomidate infusion increased, but there were no significant changes in adrenaline, noradrenaline, or hemodynamic values. As etomidate administered at $10 \mu \mathrm{g} \cdot \mathrm{kg}^{-1} \cdot \mathrm{min}^{-1}$ for $3 \mathrm{~h}$ had minimal effect on adrenocortical and adrenal medulla function, use of etomidate at this dose may be safe for anesthesia maintenance.

We did not perform ACTH stimulation tests in this experiment, mainly because pre-anesthetic testing in the study dogs revealed normal adrenal function. However, this is a limitation of our experiment.

\section{Conclusion}

In summary, the study showed that cortisol and aldosterone levels decreased with time and continuous infusion of various etomidate in dogs under general anesthesia; there were no significant changes in adrenaline and noradrenaline levels, HR, MAP, and BIS in any group. These results provide reference for clinical application.

\section{Abbreviations}

HR: Heart rate; MAP: Mean arterial pressure; BIS: Bispectral index; ICU: Intensive care unit; CVP: Central venous pressure.

\section{Competing interests}

The authors declare that they have no competing interests.

Authors' contributions

$\mathrm{BQ}$ designed the study and wrote the paper; $\mathrm{HH}$ and $\mathrm{BC}$ performed the study; $\mathrm{HH}$ and $\mathrm{ZZ}$ analyzed the data. All authors read and approved the final manuscript.

\section{Acknowledgement}

This study was supported by the Guizhou Province Science and Technology Department for Social Development Public Relations Projects (20093057).

Received: 27 January 2015 Accepted: 30 December 2015 Published online: 08 January 2016

References

1. Keim SM, Erstad BL, Sakles JC, Davis V. Etomidate for procedural sedation in the emergency department. Pharmacotherapy. 2002;22:586-92.

2. Heinrich S, Schmidt J, Ackermann A, Moritz A, Harig F, Castellanos I. Comparison of clinical outcome variables in patients with and without etomidate-facilitated anesthesia induction ahead of major cardiac surgery: a retrospective analysis. Crit Care. 2014;18:R150.

3. Thompson Bastin ML, Baker SN, Weant KA. Effects of etomidate on adrenal suppression: a review of intubated septic patients. Hosp Pharm. 2014:49:177-83.

4. Erdoes G, Basciani RM, Eberle B. Etomidate-a review of robust evidence for its use in various clinical scenarios. Acta Anaesthesiol Scand. 2014;58:380-9.

5. Masoudifar M, Beheshtian E. Comparison of cardiovascular response to laryngoscopy and tracheal intubation after induction of anesthesia by Propofol and Etomidate. J Res Med Sci. 2013;18:870-4. 
6. Wagner CE, Bick JS, Johnson D, Ahmad R, Han X, Ehrenfeld JM, et al. Etomidate use and postoperative outcomes among cardiac surgery patients. Anesthesiology. 2014;120:579-89.

7. Hildreth AN, Mejia VA, Maxwell RA, Smith PW, Dart BW, Barker DE. Adrenal suppression following a single dose of etomidate for rapid sequence induction: a prospective randomized study. Trauma. 2008;65:573-9.

8. Kamp R, Kress JP. Etomidate, sepsis, and adrenal function: not as bad as we thought? Crit Care. 2007;11:145.

9. Ehrman R, Wira C, Lomax A, Hayward A, Marcelin J, Ellis T, et al. Etomidate use in severe sepsis and septic shock patients does not contribute to mortality. Intern Emerg Med. 2011;6:253-7.

10. Ray DC, McKeown DW. Etomidate for critically ill patients. Pro: yes we can use it. Eur J Anaesthesiol. 2012;29:506-10.

11. van den Heuvel I, Wurmb TE, Böttiger BW, Bernhard M. Pros and cons of etomidate-more discussion than evidence? Curr Opin Anaesthesiol. 2013;26:404-8.

12. Majesko A, Darby JM. Etomidate and adrenal insufficiency: the controversy continues. Crit Care. 2010;14:338.

13. Jones AE. The etomidate debate. Ann Emerg Med. 2010;56:490-1.

14. Bowman WC. Neuromuscular block. Br J Pharmacol. 2006;147 Suppl 1:S277-86.

15. Pessina P, Fernández-Foren $A$, Cueto E, Delucchi L, Castillo V, Meikle A. Cortisol secretion after adrenocorticotrophin (ACTH) and Dexamethasone tests in healthy female and male dogs. Acta Vet Scand. 2009;51(1):33.

16. Morato T, Beltrán M, Caballero R, Cárdenas A, Fuentes $\mathrm{S}$, Mendoza F, et al. Half-life of blood cortisol in normal subjects. Rev Invest Clin. 1970;22(4):355-63.

17. Scavo D, lacobelli A, Giovannini C, Cugini P. Aspects of adrenal cortex function in obesity. IV. Research on urinary aldosterone and tetrahydroaldosterone and on the half-life of plasmatic aldosterone. Folia Endocrinol. 1967;20(2):164-74.

18. Yalow RS, Glick SM, Roth J, Berson SA. Radioimmunoassay of human plasma ACTH. J Clin Endocr Metab. 1964;24(11):1219-25.

19. Doenicke A, Roizen MF, Hoernecke R, Mayer M, Ostwald P, Foss J. Haemolysis after etomidate: comparison of propylene glycol and lipid formulations. Br J Anaesth. 1997;79:386-8.

20. Forman SA. Clinical and molecular pharmacology of etomidate. Anesthesiology. 2011;114:695-707.

21. Johnson KB, Egan TD, Layman J, Kern SE, White JL, McJames SW. The influence of hemorrhagic shock on etomidate: a pharmacokinetic and pharmacodynamic analysis. Anesth Analg. 2003;96:1360-8.

22. Bovill JG. Intravenous anesthesia for the patient with left ventricular dysfunction. Semin Cardiothorac Vasc Anesth. 2006;10:43-8.

23. Lipiner-Friedman D, Sprung CL, Laterre PF, Weiss Y, Goodman SV, Vogeser $M$, et al. Adrenal function in sepsis: the retrospective Corticus cohort study. Crit Care Med. 2007;35:1012-8.

24. Cuthbertson BH, Sprung CL, Annane D, Chevret S, Garfield M, Goodman S, et al. The effects of etomidate on adrenal responsiveness and mortality in patients with septic shock. Intensive Care Med. 2009:35:1868-76.

25. Jackson Jr WL. Should we use etomidate as an induction agent for endotracheal intubation in patients with septic shock?: a critical appraisal. Chest. 2005;127:1031-8.

26. Walls RM, Murphy MF. Clinical controversies: etomidate as an induction agent for endotracheal intubation in patients with sepsis: continue to use etomidate for intubation of patients with septic shock. Ann Emerg Med. 2008:52:13-4

27. Toklu S, Iyilikci L, Gonen C, Ciftci L, Gunenc F, Sahin E, et al. Comparison of etomidate-remifentanil and propofol-remifentanil sedation in patients scheduled for colonoscopy. Eur J Anaesthesiol. 2009;26:370-6.

\section{Submit your next manuscript to BioMed Central and we will help you at every step:}

- We accept pre-submission inquiries

- Our selector tool helps you to find the most relevant journal

- We provide round the clock customer support

- Convenient online submission

- Thorough peer review

- Inclusion in PubMed and all major indexing services

- Maximum visibility for your research

Submit your manuscript at www.biomedcentral.com/submit
Biomed Central 